\title{
Functional Resource Model Enables FleXible OfFer Processing
}

\section{DUERR, H.; TrAN, N.; UnGER, K.; MilitZER, J. \& TEICH, T.}

Abstract: To cope with intensified competition along global production networks, prompt and precise offers concerning technologic or economic feasibility for an individual product demand is needed. Therefore, this paper will first briefly present the three-columned research project: the customer's performance request, the functional description of company resources, and enhanced ERP modules to match both sides. The structure and the functional adaptation of the resource model is considered more detailed in this paper, because it enables the scalability of manufacturing resources by the use of technical or economic production functions $(P F)$ and could be implemented in the textile industry. This will help implementing a firm's real technological capability, being able to answer product requests and transfer them into expected planning environment automatically.

Key words: machining features, textile resources, production functions, manufacturing, capability
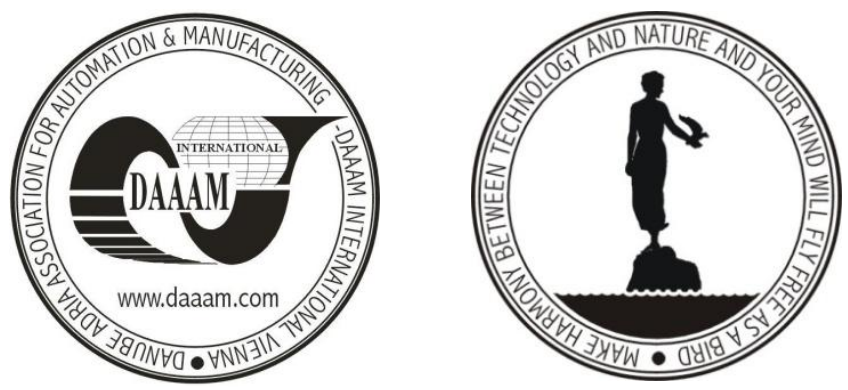

Authors' data: Prof. Dr.-Ing. habil. Duerr, H[olger]**; Tran, N[goc-Anh]**; Unger, K[atja]*; Militzer, J[oerg]*; Prof. Dr. rer.pol. habil. Teich, T[obias]*; *University of Applied Sciences Zwickau, Dr.-Friedrichs-Ring 2a, 08056 Zwickau, Germany, **Chemnitz University of Technology, Reichenhainer Str. 70, 09107 Chemnitz, Germany, Katja.Unger@fh-zwickau.de, Joerg.Militzer@fh-zwickau.de, Tobias.Teich@fh-zwickau.de; Holger.Duerr@mb.tu-chemnitz.de, Ngocanh.tran@mb.tu-chemnitz.de

This Publication has to be referred as Duerr, H[olger]; Tran, N[goc-Anh]; Unger, K[atja]; Militzer, J[oerg] \& Teich, T[obias] (2010). Functional Resource Model Enables Flexible Offer Processing, Chapter 01 in DAAAM International Scientific Book 2010, pp. 001-008, B. Katalinic (Ed.), Published by DAAAM International, ISBN 978-3-901509-74-2, ISSN 1726-9687, Vienna, Austria

DOI: $10.2507 /$ daaam.scibook.2010.01 


\section{Introduction}

Not only for bigger companies but also for small and medium enterprises (SMEs) the attraction of new business is an essential success factor in highly competitive value-added production networks. In recent years mass customization (MC) has advanced to a key strategy to offer customers more choice (Ismail et al., 2007). The present trend to individualization means matching customer's individual needs, forces especially SME's to improve their manufacturing agility and product flexibility to finally benefit from cross-company cooperation and planning. The authors detected a gap between wanted agility and individual product design and manufacturing, that is covered by their research to lower response times for individual demand and to assure manufacturing abilities to be more adaptive.

This paper deals first with an overview of the project and the methodical framework for an automated offer preparation process that results in short response times. To improve the needed manufacturing agility, the structure and functionality of the functional resource model is outlined in the second part.

\section{Research Placement}

Some publications refer to manufacturing capability for computer aided engineering (CAE) support and differentiate between manufacturing resources, processes and strategies (Molina et al., 1995). This context is similar to ours, but strategies are outlined because of the operative focus of the offer preparation process.

As one of the key components CAD/CAM integration, CAPP systems, and feature technology were already contemplated (Gao \& Huang, 1996). The latter is an important element for the presented functional resource model the authors are developing within a research project between the University of Applied Sciences Zwickau and the Chemnitz University of Technology. The following drawing illustrates the tripartite focus of research (figure 1), whereas the functional resources implementation is embedded on the right side. Together with the description of a product demand on the left side, ERP modules are enhanced for generating, scheduling and evaluating process variants to benefit from adapting functional resources.

\subsection{Performance Request}

A customer's performance request consists of general customer data, a CAD model with required product characteristics, and order-specific information, e.g. price expectations and quantity. Already done is product model design based on STEP, enabling standardized product model data (Amaitik et al., 2005). The named project uses features to limit the design engineer according to the abilities of manufacturing resources, already published by the concept of SBDCR (Teich et al., 2008a).

\subsection{Resources Offer}

The right pillar is the functional description of company resources, where the available operating facilities and equipment with their capabilities are represented in 
an innovative manner - as character-changing competence cells. An evaluation of technical and economic PFs will be provided in this paper and helps to integrate static and dynamic influences in offering.

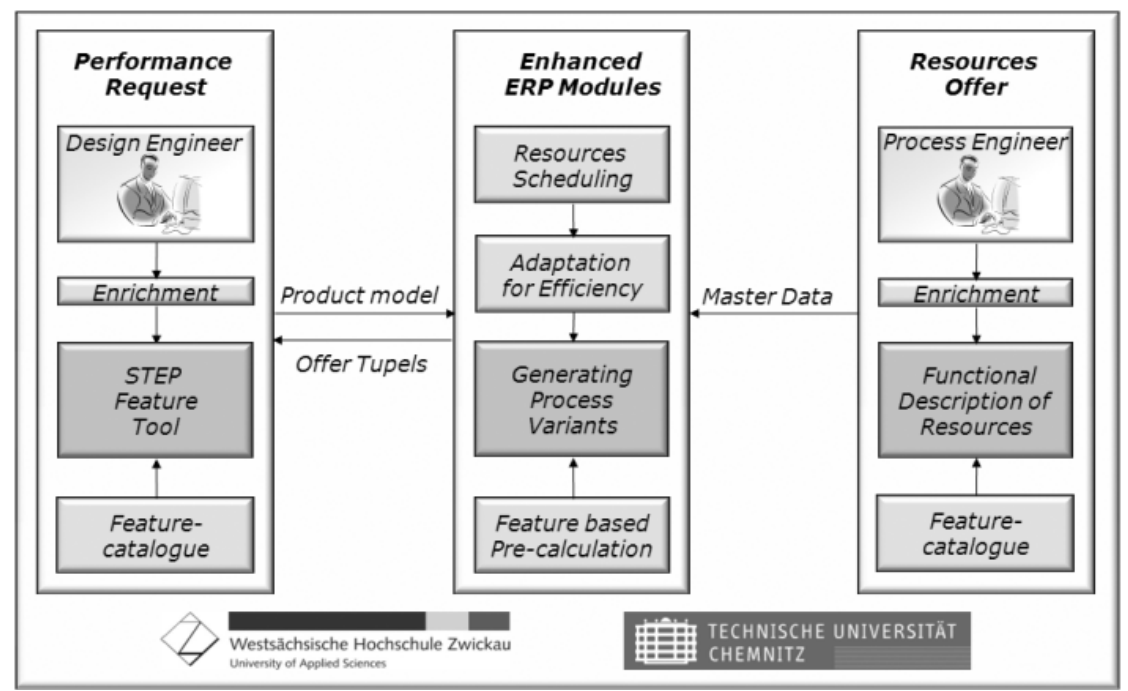

Fig. 1. Three-columned research project

\subsection{Resources Offer}

The right pillar is the functional description of company resources, where the available operating facilities and equipment with their capabilities are represented in an innovative manner - as character-changing competence cells. An evaluation of technical and economic PFs will be provided in this paper and helps to integrate static and dynamic influences in offering.

The Authors set up a classification for the relevant manufacturing elements, according to their contribution to the value-added process in terms of transformation, transport or storage. It is differentiated in personnel for the production process, materials and physical means of production, including machines, instruments, measuring equipment and means of conveyance or stock equipment. Most interesting is the combination of workforce and several means of production as competence bundles with their ability to transform by using several manufacturing techniques. This resource bundle in a competence point of view goes back to the theory of competences of Erpenbeck (Erpenbeck, 1999).

The main focus underlies modelling the characterization of machines and instruments that have an impact on specific product related criteria by manufacturing methods' parameters. All resources contribute to change geometrical and technological attributes by using manufacturing methods. Other resources illustrate the transportation or handling capability, so the shared production process will be calculable in future research. For modelling resources, so called manufacturing features will be used. These types of design features are complex information structures that extend the construction features of the described demand to set up a technological knowledge base. That means, the sequence of operations within the technological process variants can be determined easier. For operationalizing the enrichment of resources' description, the manufacturing features can be assigned to the methods itself in a static manner of modelling. This is important for continuous 
processing, because there is no enterprise resource planning system available at the moment that supports an integrated resources description for a forecast precalculation based on feature design.

Another key point of functional modelling resources is the dynamic component that evaluates the process variants with production functions. The evaluated output of a manufacturing process is dynamic, because the marginal costs afford a time and quantity dependent adaption of the output (Käschel \& Teich, 2004). Additionally, the technical funding of consumption functions helps to vary technical parameters of each manufacturing method (Sonntag, 2004). That is the second fact no ERP system provides an integrated solution for production function in evaluation and scheduling of potential offers so far.

The physical marginal product of the input factors (labour and capital) enables the minimum increasing of one input factor and assumes that all other factors can be kept constant. So the approach is usable for process variants that can be scalable by a wide variety of the parameters that comes with the manufacturing methods itself. The output quantity will increase for about one unit of labour, whereas the capital factor can be reduced. That means, implementing this production function will lead to adaptive offers where the input factors are in a functional relationship within one technological process variant. This relationship has to be created for the technological knowledge base, where the characteristics of manufacturing features change as the input factors above. The effect is that the authors are developing an approach acting dynamically to the requirements of product quantity and delivery date for example.

\subsection{Enhanced Planning Environment}

To make a use of modelling resources and customer requests in a functional way, enhanced ERP modules are being created to present concrete offers to customers. First module is the generation of process variants (PVP) and production plans, combined with an initial measurement by a matrix of economical requirements, done by ant colony algorithms for multi-criteria optimization problems. In the module pre-calculation the costs will be calculated in a feature based way. Each generated variant is scheduled with extracted orders from an existing ERP/SCM system (Teich et al., 2008b) to evaluate capacity restrictions of the resources. Finally, the customer gets a representation of possible solutions as concrete offers, varying by price, date and delivery conditions as well as product implementations.

To compare the functionally modeled supply and demand is the most important step, after representing the technical environment. Modern algorithms of ant colonies (heuristics) will be evaluated for the complex information retrieval process and will help to get appropriate solutions. The module that comes up for matching provides generated work schedules and process variant plans (PVP) that are based on manufacturing features. That means that this step also creates routings and several different variants to build a product. For example, a hole can be made by milling, drilling or other chemical processes relying on the given requirements of the product model. So we can imagine that different technologies in combination with suitable materials, machines, tools and apparatuses cause different work schedule patterns and 
variants. The key element for the technical potential can be tapped in with the given resources, functionally modeled with their range of competences.

\section{Adaptive Resource Model}

The greatest benefit for a flexible preparation of offers comes from the adaptation of PFs, because benchmarked process variants will be rescheduled after time, factor and parameter-oriented scalability. This adaptation is considered more deeply in the next paragraph. To explain the structure and functionality of the adaptive resource model, the authors refer to Competence Cells (CC) which is an educational term for representing abilities (Erpenbeck \& Heyse, 1999). These abilities have to be transferred to a manufacturing context, where PFs are used to describe the scalable behaviour of CCs to flexibilize the preparation of offers.

\subsection{Structural Assignment}

The company resources - so called character-changing competence cells (4Cs) - have an indirect impact on the products' attributes. More precisely, the resources are bundled in Competence Cells and characterised by their parameters (general and specific ones) according to the manufacturing method or to its physical properties and conditions. These parameters with interdependences are encapsulated in so called manufacturing features. A design feature in its product-related view mainly refers only to its geometric and technological attributes, not to adaptive parameters of the production process.

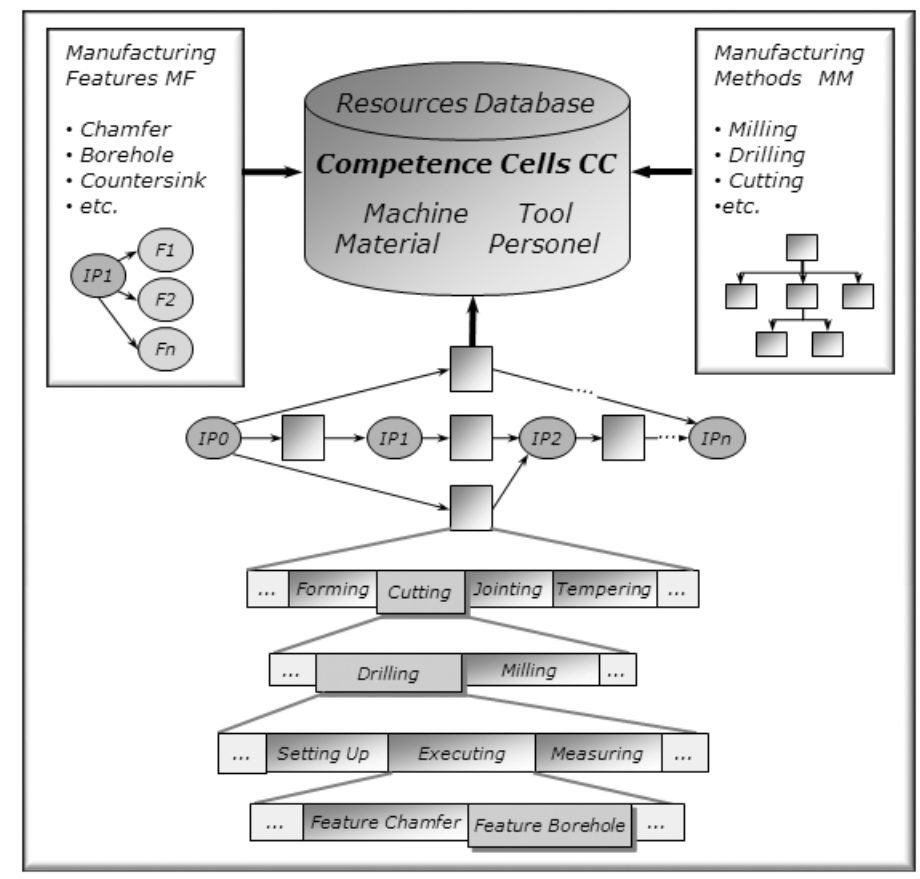

Fig. 2. Assigning CC to MF and to MM

As mentioned before, enhanced ERP modules generate and schedule PVPs. To break this alternative plan down, intermediate products (IPs) with Features are connected by different process categories. They are to disaggregate into 
manufacturing stages and those again to process elements characterized by manufacturing methods that constitute a granular operation of a work schedule (figure 2).

\subsection{Structural Assignment}

Another important element is the integration of technical and economic production functions from the theory of production. Most significant influences come from GUTENBERG who created a limitational production function that describes the consumption of factors and considers technical influences of the operating facilities. $\mathrm{He}$ also introduces the theory of adaptation for quantity, time and intensity. The elaboration of them is used to identify unused potential of resources' combination. Most relevant is the technical funding of GUTENBERG that evolves technical set values as adaptable parameters (Sonntag \& Steven, 2005). Based on the structural assignment, technical PFs define each process step and cover consumption factors as input, a process step itself as throughput as and the production rate as output factor (figure 3).

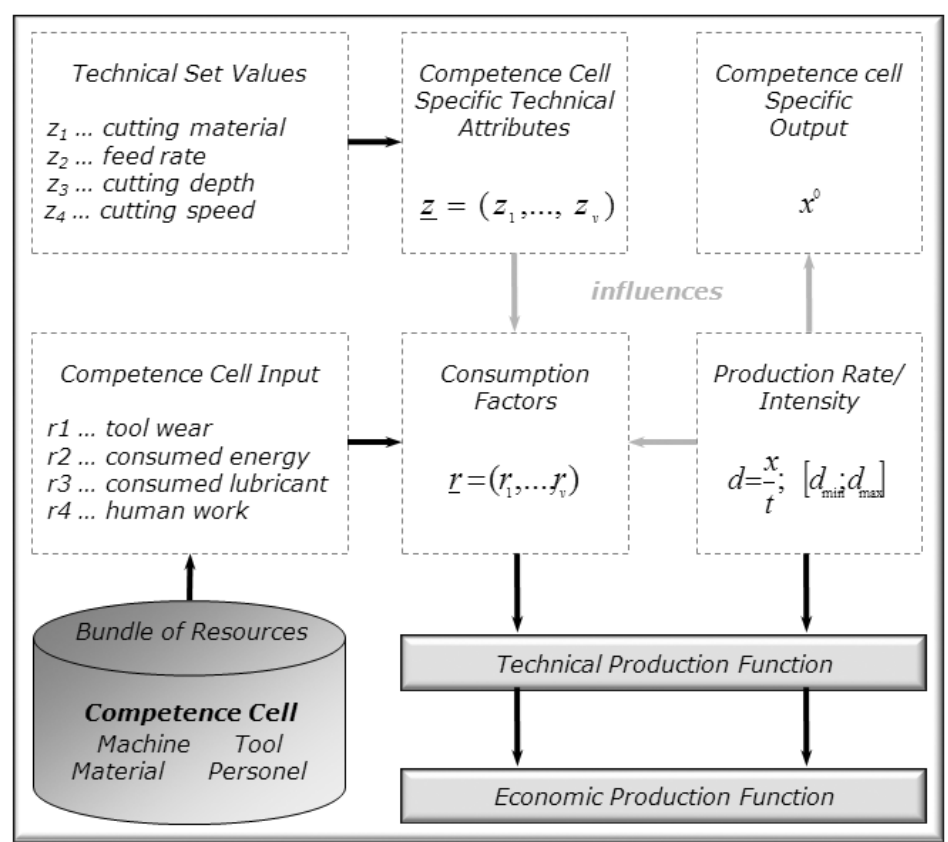

Fig. 3. Technical and economic PF

Each process step is characterized by only technical efficient possibilities. However, a technical less efficient variant can be more economical. Evaluating this, it requires adapting the production rate, technical set values, or time to influence the output factors of a process step. In our model the technical PF are to transform into economic ones for re-scheduling and re-evaluating process variants.

\section{Performance Request and Resources Offer in Textile Sector}

To describe a performance request for finished textile area-measured material a new demand structure has to be created, including customer requirements and a full detailed specification of the desired product. This implicates all necessary 
characteristics and technological conditions. Feature Technology from the engineering context helps to design a catalogue of textile features with the use of a generative grammar. For example the feature "fibre" with a special bond type as an attribute can be selected to describe the initial raw material for finishing processes. All textile features in a generative form of grammar can finally constitute the textile product model. Very important to note is, that all features are based on the resources of a supplier specification with scalable attributes. That means the missing software support in textile design shows the gap of application-dependent file formats, used for processing product model data. For this reason, the authors are developing a software tool to meet all structural requirements. The prototypic implementation of the example "linen" out of finished cotton was realized as a product structure.

Especially in the textile industry, the authors detected a gap between "just knowing" about all present manufacturing abilities (technical, economical, ecological point of view) and utilising that knowledge completely for a resources offer. The abilities are often not well prepared or adequate documented for an automated offering process with short reaction times. Making that knowledge continuously available and later integrating it into an enterprise resource planning environment has to be considered. A knowledge base for textile technologies, mainly designed by using manufacturing textile features, will be set up (Gebhardt, et al, 2006). The effects of substituted input factors within suitable process variants show a flexible use of consumed input energy, textile materials, machines and their supplies for example, so that the input factors are temporal and quantitative adapted to customers preferences concerning price and delivery data for example. Newer developments also consider to vary technical variables of the technology and to verify their effects to GUTENBERGS production function (Sonntag, 2004).

After modelling a technical function of consumption an economic function has to be developed for calculating factor prices. Besides KLOOCK's reflections of a cross-corporate manufacturing the relevance of alternative production processes are to be evaluated. The authors recognize the vertical substitutionality of production processes as alternating technologies down to process steps as one of the most important facts. The authors also consider "Engineering Production Functions" which were developed to consider the technical scientific laws of transformations at a low value-added level. To evolve such technical functions the whole production process has to be divided into his elemental chemical and or physical process steps, as it is useful for basic finishing technologies.

Quite difficult are alternating influences and transformations of mechanic, thermal, electric and chemic energies, present limitations of our research, but plays an important role for finishing processes, because chemical and physical methods are obviously relevant for generating value-added at this fabricating level (Fandel, 2005).

\section{Conclusion}

The functional resource model should enable an efficient and dynamic use of manufacturing capabilities, embedded in the framework for generating additional orders with reduced response times in a value-added production network. For 
modeling holistic technological performance, this paper considers the technical feasibility and its quantitative evaluation within the textile chain. The integration of relevant production functions enables to create an adaptive functional resource model with an integrated knowledge of producible textile features and their constraints through technical parameters of technology chains. Present work themes include a prototypic implementation of the framework, the preparation of an UML resource model and filling a database for turning operations/ competences. For further research, the scalability of the resources model to other fields of application will be analyzed and evaluated.

\section{References}

Amaitik, S.M.; Kilic, S.E. (2005). STEP-based feature modeler for computer -aided process planning. In: International Journal of Production Research, Vol. 43, No.15, Taylor \& Francis Group Ltd., London, p. 3087-3101

Erpenbeck, J.; V. Heyse (1999). The biography of competences. Waxmann Publishing, New York, Munich

Fandel, G. (2005). Produktion I. Heidelberg/ Berlin, Springer Pub., pp. 119-187.

Gao, J. X.; Huang, X. X. (1996). Product and manufacturing capability modeling in an integrated $\mathrm{CAD} /$ process planning environment, In: The International Journal of Advanced Manufacturing Technology, Vol. 11, pp. 43-51

Gebhardt, R.; Barteld, M.; Erth, H.; Teich, T.; Trommler, U. (2006). VITEX - Virtual Enterprises in the Textile Chain, in: Proceedings of the 6th World Textile Conference AUTEX 2006; Raleigh (NC, USA), June 11-14 2006.

Ismail, H.; Reid, I. R.; Mooney, J.; Poolton, J.; Arokiam, I. (2007). How Small and Medium Enterprises Effectively Participate in the Mass Customization Game, In: Engineering Management, IEEE Transactions on, Vol. 54, pp. 86-97

Käschel, J.;Teich, T. (2004): Production Economics, GUC-Publishing, p. 33

Molina, A.; Ellis, T.; Young, R.; Bell, R. (1995). Modelling Manufacturing Capability to Support Concurrent Engineering, In: Concurrent Engineering, Vol. 3, No. 1, SAGE Publications, pp. 29-42

Sonntag, S. (2004). Gutenberg's production function: Their characteristics and Technical Fundings. German University Publishing, Wiesbaden, Gabler Edition Wissenschaft, Dissertation, ISBN: 3-8244-8099-9

Sonntag, S.; Steven, M. (2005). Technical Fundings of Gutenberg's production function, In: Quantitative business management, Physica Publishing, pp. 159183

Teich, T.; Militzer, J.; Zimmermann, M.; Unger, K. (2008a). SBDCR for Standardization of Customer Requests, In: Proceedings of the Fifteenth International Working Seminar on Production Economics, Vol. 1, pp. 495-503

Teich, T.; Militzer, J.; Unger, K.; Gaese, T.; Winkler, S. (2008b). A formalized approach for generating customer offers based on heuristic methods, In: Logistics and Supply Chain Management: Trends in Germany and Russia, Proceedings of the German-Russian Logistics Workshop, Publishing House of the Saint, pp. 272-282, Petersburg State Polytechnical University 